\title{
Extrusion Process of Polypropylene Composites Reinforced Milled Carbon Fibre for Conductive Polymer Composite Application
}

\author{
Nabilah Afiqah Mohd Radzuan ${ }^{1, *}$, Abu Bakar Sulong ${ }^{1,2}$, and Mahendra Rao Somalu ${ }^{1}$ \\ ${ }^{1}$ Fuel Cell Institute, Universiti Kebangsaan Malaysia, 43600, UKM Bangi, Selangor, Malaysia \\ ${ }^{2}$ Centre for Materials Engineering and Smart Manufacturing, Mechanical Engineering Programme, \\ Faculty of Engineering and Built Enviroment, Universiti Kebangsaan Malaysia, 43600, UKM \\ Bangi, Selangor, Malaysia
}

\begin{abstract}
A polypropylene (PP) reinforced milled carbon fibre (MCF) was developed to produce high conductive polymer composites. Theoretically, by altering the filler orientation, the electrical conductivity and mechanical properties can be controlled. However, the orientation techniques which influence the MCF fibre are difficult to performed. Therefore, this study focused on controlling the filler orientation through the extrusion process. Hence, the extrusion temperature of $230^{\circ} \mathrm{C}$ and rotational speed of $50 \mathrm{rpm}$ at $70 \mathrm{wt} . \%$ of MCF and $30 \mathrm{wt} . \%$ of PP were used. The electrical conductivity in perpendicular to the extrusion direction was higher at $2.0 \mathrm{~S} / \mathrm{cm}$ as compared to $0.66 \mathrm{~S} / \mathrm{cm}$ in the parallel direction. Besides, the extruded composite of rod and sheet were studied in which rod dies offers higher electrical conductivity of $3.0 \mathrm{~S} / \mathrm{cm}$ and better mechanical properties of 1225 $\mathrm{MPa}$ than the sheet dies. Alteration in filler orientation aid in enhancing the electrical conductivity as minimum fillers breakage occurred due to the low shear rate of $2.2 \mathrm{~s}^{-1}$ which indirectly induces the filler to the desired orientation. Therefore, the extrusion process able to improve the electrical conductivity and mechanical properties of composite materials, as the filler oriented perpendicular to extrusion direction.
\end{abstract}

\section{Introduction}

Conductive polymer composites (CPCs) have been extensively studied for various field of application due to its remarkable features and performance [1]. In order to produce a highly conductive material, the conductive phase above the critical value is needed to ensure composite material stay electrically conductive [2]. However, the electrical conductivity of CPCs material depends on many factors including filler volume faction, filler shape and size, filler orientation, shear rate and the morphology of the matrix. The optimization of the processing parameter is a method which influence the electrical conductivity and mechanical properties of the CPC. Recently, compression molding and injection molding are the two common technique used to fabricate CPC materials [3]. Although this method has been used

\footnotetext{
*Corresponding author:afiqah@ukm.edu.my
} 
extensively, studied shows that pre-mixing process are able to enhance the electrical and mechanical performance of the CPCs [2]. This pre-mixing process is crucial for achieving a proper filler dispersion in polymer matrix, modest shear forces and increase the ability to form a homogeneous matrix in combination with polymer resin [4, 5]. Extrusion process using twin screw extruder has been used widely in various industries including polymer processing and food processing due to its ability to run multiple processes that can be conducted continuously [6]. Parameters including shear rate, temperature and filler aspect ratio need to be considered in order to optimize the extrusion process. In this study, to ensure a highly electrically conductive polymer composite optimum die configurations were studied and analyzed.

\section{Methodology}

\subsection{Materials and Fabrication Process}

Milled carbon fibre (MCF), Grade CFP-7-50 was supplied by ShenZhe Yataida High-Tech. Co. Ltd.with a diameter of $9 \mu \mathrm{m}$, average length of $300 \mu \mathrm{m}$, aspect ratio of 43 and a density of $1.75 \mathrm{~g} / \mathrm{cm}^{3}$. Meanwhile, the polypropylene (PP) selected as a binder in this study was supplied by Goonvean Fibres Ltd. due to its extraordinary properties; mechanical strength, low density, electrical resistance, and greater permeability by gases [1]. This PP polymer has a maximum average size of $90 \mu \mathrm{m}$, density of $910 \mathrm{~kg} / \mathrm{m}^{3}$ and melting index of $10 \mathrm{~g} / 10 \mathrm{~min}$ at $160{ }^{\circ} \mathrm{C}$. The PP was supplied in powder form with grade number Titan-600. Initially, the PP powder and the MCF, were pre-mixed based at $30 \mathrm{wt} . \%$ of PP and $70 \mathrm{wt} . \%$ of MCF. The premixed process was conducted using a mechanical mixer (Model RM 20-KIKA-WERK) at room temperature before being melt extruded using a twin-screw extruder, (Thermo Haake TSE Twin-Screw Extruder). The extruder was set at a temperature of $230{ }^{\circ} \mathrm{C}$ with a rotational speed at $50 \mathrm{rpm}$ for 30 minutes using a different dies shapes [2]. The fibre orientations were analysized using the field emission scanning electron microscope (FESEM) (Zeiss Supra55VP, Germany). Meanwhile, the electrical conductivity was measured for both in-plane conductivity using Jandel four-point probe and an RM3 test unit [4-6].

\subsection{Simulation of pre-mixing process}

This study focused on three main dies configuration which are shapes and dimensions. Hence, series of simulation has been conducted to verify the pre-mixed process and its ability to orientate the fibre. The simulations were performed using the MoldFlow simulations software in which the input data were fist sketched using the AutoCAD Inventor. The dimensions of $3 \mathrm{~mm}$ and $5 \mathrm{~mm}$ opening diameter with rod and sheet shapes were considered in this study.

\section{Results and Discussions}

The simulations conducted were shows in Figure 1, in which the different fibre orientations within the polymer matrix were exposed. Previous studies on fibre orientations reported that the fibre orientation were depends on the dies opening and the shapes used [9]. As shows in Figure 1(c), rod die demonstrates the highest fibre orientation at parallel to the extrusion directions compared to the sheet dies at various die opening. These exhibited that the fibre tends to orientate in converging die compared to diverging die and results in fibre to orientate parallel to extrusion directions [10]. Differ results shows in sheet dies in Figure 1 (a) and 
Figure 1 (b) in which the fibre tends to orientate randomly within the process. This phenomenon was reported in previous studies in which the diverging dies will developed a fibre deformations and results in random fibre orientations [11]. Despite that, the die opening thickness also contribute in fibre orientations. As the die opening thickness reduces from 5 $\mathrm{mm}$ to $3 \mathrm{~mm}$, the fibre tends to become compact and compress. These further results in fibre to orientate parallel to extrusion directions. Moreover, Figure 1 also indicated the orientation tensor of each fibre at different die configurations. As shown in Figure 1, rod die exhibited highest orientation tensor at 0.9337 compared to other $5 \mathrm{~mm}$ and $3 \mathrm{~mm}$ sheet dies at 0.9243 and 0.9254 , respectively. Hence, these simulations demonstrate that the experimental performed will encounter these similar results.
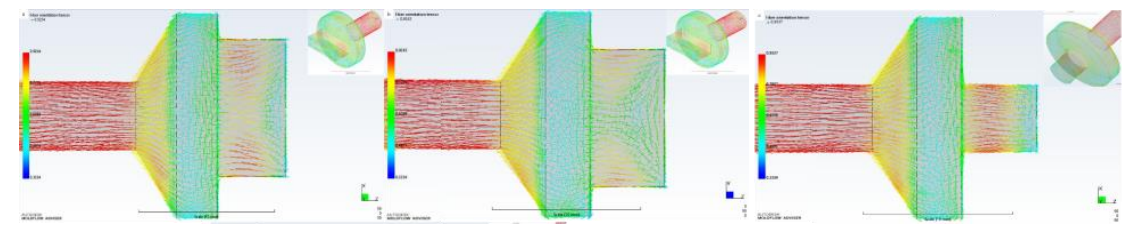

Fig. 1. Fibre orientation simulations of (a) $3 \mathrm{~mm}$ sheet die, (b) $5 \mathrm{~mm}$ sheet die and (c) $5 \mathrm{~mm}$ rod die.
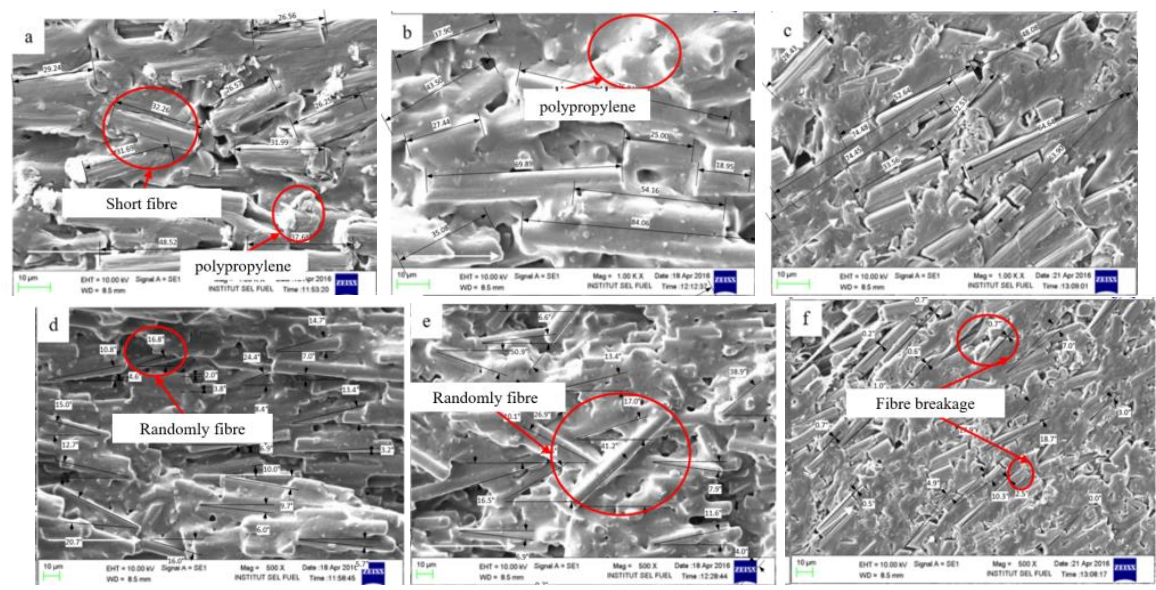

Fig. 2. Microstructural analysis at $1.0 \mathrm{~K} \mathrm{X}$ observations for (a) $3 \mathrm{~mm}$ sheet die, (b) $5 \mathrm{~mm}$ sheet die and (c) $5 \mathrm{~mm}$ rod die, while at $500 \mathrm{X}$ observations for (d) $3 \mathrm{~mm}$ sheet die, (e) $5 \mathrm{~mm}$ sheet die and (f) $5 \mathrm{~mm}$ rod die

Based on the simulation conducted, Figure 2 (a) and Figure 2 (b) shows the FESEM images in which the fibre tends to randomly orientate when using the sheet dies. The randomly orientated fibre was caused by the high shear stress which transfer into the fibre as the die opening were decreased. Hence, these results on fibre deformations especially at the die surfaces which result the fibres to randomly orientated [10-12]. Recent studies reported that the fibre which travel using the slit die will results in more randomly orientated fibre [12]. Despite that, Figure 2 (a) shows the higher fibre brakeage experience compared to Figure 2 (b). These are because the high shear rate was developed as the die opening were decreased. These were shown by Figure 2(b) of the sheet die with $5 \mathrm{~mm}$ die opening which experience the fibre length of $42 \mathrm{~m}$. Meanwhile, the $3 \mathrm{~mm}$ sheet die experience extreme fibre breakage at $28 \mathrm{~m}$ of fibre length. In contrast, Figure 2 (c) indicated the fibre length of $55 \mathrm{~m}$, which are the longest among all the dies used. These occurred due to the converging 
die which enable the fibre to orientate uniformly within the polymer matrix $[10,12]$. Figure 2 (d) and Figure 2 (e) shows the sheet dies at $3 \mathrm{~mm}$ and $5 \mathrm{~mm}$ die opening in which the orientation angles are far below the $90^{\circ}$. Studies reported that the reduced in orientation angles indicated that the fires tend to orientate randomly due to high viscosity, low shear rate, and longer cooling time [13]. Table 1 shows the electrical conductivity of the composite materials at different die configurations. The findings are significant with the microstructural and simulation analysis. The rod die exhibited the highest electrical conductivity with 3.66 $\mathrm{S} / \mathrm{cm}$, while $3 \mathrm{~mm}$ sheet die and $5 \mathrm{~mm}$ sheet die offered $0.56 \mathrm{~S} / \mathrm{cm}$ and $1.26 \mathrm{~S} / \mathrm{cm}$, respectively. The excellent in performance occurred on the rod dies was due to the fact that the fibre able to orientate uniformly within the polymer matrix. Recent study suggested that this phenomena was due to the electron tunnelling as the fibre developed an excellent conducing pathways [15].

Table 1. Electrical conductivity at different die configurations

\begin{tabular}{|c|c|}
\hline Die & $\begin{array}{c}\text { Electrical } \\
\text { conductivity }\end{array}$ \\
\hline $3 \mathrm{~mm}$ sheet & $0.56 \mathrm{~S} / \mathrm{cm}$ \\
\hline $5 \mathrm{~mm}$ sheet & $1.26 \mathrm{~S} / \mathrm{cm}$ \\
\hline $5 \mathrm{~mm} \mathrm{rod}$ & $3.66 \mathrm{~S} / \mathrm{cm}$ \\
\hline
\end{tabular}

\section{Conclusions}

The experimental conducted shows an excellent correlation when compared to the simulation developed. Studies exhibited that the extruded MCF/PP composite using a $5 \mathrm{~mm}$ rod die geometry results in better electrical conductivity due to its better fibre orientation in the converging dies. The electrical conductivity produced using the rod die is $3.66 \mathrm{~S} / \mathrm{cm}$ shows that the converging dies able to orientate the fibre parallel to the extrusion direction.

The authors gratefully thank the Universiti Kebangsaan Malaysia for the financial support to complete this study under grant number MI-2017-004.

\section{References}

1. R. Dweiri, J. Sahari, Journal of Power Sources, 171 (2): 424-432.

2. M. Y. Zakaria, A. B. Sulong, J. Sahari, H. Suherman, Composites Part B: Engineering, 83: $75-80$.

3. B.K. Kakati, D. Sathiyamoorthy, A. Verma, Int. Journal of Hydrogen Energy, 36(22): 14851-14857.

4. R. Dweiri, J. Sahari, Comp. Sci. and Tech., 68(7-8): 1679-1687.

5. N. Hu, Z. Masuda, G. Yamamoto, H. Fukunaga, T. Hashida, J. Qiu, Composites Part A: Applied Science and Manufacturing, 39(5): 893-903.

6. Y. Nakayama, E. Takeda, T. Shigeishi, H. Tomiyama, T. Kajiwara, T. Chemical Engineering Science, 66(1): 103-110.

7. A. B. Sulong, M. I. Ramli, S. L. Hau, J. Sahari, N. Muhamad, H. Suherman, Composites Part B: Engineering, 50(0): 54-61.

8. S. P. Liu, S. S. Hwang, J. M. Yeh, C. C. Hung, International Communications in Heat and Mass Transfer, 38(1): 37-43. 
9. M. Kostic, L. Reifschneider, Encyclopedia of Chemical Processing.

10. P. J. Hine, N. Davidson, R. A. Duckett, I. M. Ward, Composites Science and Technology, 53(2): 125-131.

11. G. Ausias, J. Jarrin, M. Vincent, Composites Science and Technology, 56(7): 719-724.

12. T. Köpplmayr, I. Milosavljevic, M. Aigner, R. Hasslacher, B. Plank, D. Salaberger, J. Miethlinger, Polymer Testing, 32(3), 535-544.

13. P. Pötschke, A. R. Bhattacharyya, A. Janke, European Polymer Journal, 40(1): 137-148.

14. M. Sharma, I. M. Rao, J. Bijwe, Wear, 267(5-8): 839-845.

15. J. Feller, I. Linossier, Y. Grohens, Materials Letters, 57(1): 64-71. 